\title{
Observational Study of Grand Canyon Rim-to-Rim Day Hikers: Determining Behavior Patterns to Aid in Preventive Search and Rescue Efforts
}

\author{
Emily A. Pearce, $\mathrm{BS}^{1,2}$; Lucie Jelínková, $\mathrm{BA}^{1}$; Lynne Fullerton, $\mathrm{PhD}^{1}$; Christian J. Malcolm, $\mathrm{MOL}^{2}$; \\ Hannah L. Heinrich, $\mathrm{PhD}^{2}$; Evan J. Norwil, $\mathrm{BSE}^{2}$; Adam Plate, $\mathrm{MD}^{1}$; Meryn Hall, BLA, BFA ${ }^{1}$; \\ Christopher S. Bossart, $\mathrm{MD}^{1}$; Eric Schaller, $\mathrm{BS}^{1}$; Andrew J. Harrell, $\mathrm{MD}^{1}$; Jon K. Femling, MD, $\mathrm{PhD}^{1}$ \\ ${ }^{1}$ Department of Emergency Medicine, University of New Mexico School of Medicine, Albuquerque, NM; ${ }^{2}$ Grand Canyon National Park, Preventive \\ Search and Rescue Team, Branch of Emergency Services, Grand Canyon, AZ
}

Introduction-Grand Canyon National Park has seen an increase in visitors traversing the canyon from rim to rim (R2R) in a single day. R2R hikers travel over $33.8 \mathrm{~km} \mathrm{(21} \mathrm{mi)} \mathrm{over} 3300 \mathrm{~m}$ $(11,000 \mathrm{ft})$ of elevation change and endure large temperature changes. Grand Canyon emergency medical service providers provide emergency medical services to over 1100 visitors annually. Direct guidance by Preventive Search and Rescue rangers has improved safety. The objective of this study was to examine visitors attempting an R2R traverse and to enhance PSAR rangers' anticipatory guidance.

Methods - We conducted an observational study of R2R hikers in the spring and fall of 2015. Hikers consented to study inclusion and were interviewed at the starting trailhead, canyon bottom, and exit trailhead. We performed a survey and collected biometric data.

Results-We enrolled 617 visitors with a median age of 43 y (interquartile range [IQR] 33-53); 65\% were male and $46 \%$ had hiked the R2R a median number of 3 times previously (IQR 2-7). Hydration strategies included water bottle only (20\%), hydration bladder only (31\%), and both water bottle and hydration bladder (48\%). R2R crossers had an average start time of 0530 (SD $1.3 \mathrm{~h}$ ) and median crossing time of $11.9 \mathrm{~h}$ (IQR 10.7-13.3). Crossing time and self-reported fatigue were negatively correlated with prior R2R experience $(P=0.02)$.

Conclusions - Crossing R2R in a day is hazardous and associated with risk of injury and illness. The results of this study can be used by Preventive Search and Rescue to reduce these risks by educating hikers.

Keywords: hiking, trail running, hydration

\section{Introduction}

Hiking populations have previously been studied in the context of musculoskeletal injury ${ }^{1-3}$ and high-altitude illness, ${ }^{4}$ but few studies have examined injury prevention $^{5-8}$ or the epidemiology of hiking-related illness of hikers or backpackers. ${ }^{9,10}$ Furthermore, there is limited literature on injury or illness prevention in hikers in a desert wilderness environment. ${ }^{7,8}$

Corresponding author: Jon K. Femling, MD, PhD, Department of Emergency Medicine University of New Mexico, MSC11 6025 1, University of New Mexico, Albuquerque, NM 87131-0001; e-mail: jfemling@salud.unm.edu.

Submitted for publication February 2018.

Accepted for publication August 2018.
Grand Canyon National Park (GRCA), located in remote northern Arizona, is visited annually by over 6 million people and is an especially hazardous setting for environment-associated illnesses. Temperatures at the bottom of the canyon can reach $48^{\circ} \mathrm{C}\left(120^{\circ} \mathrm{F}\right)$ in the shade with temperatures regularly climbing above $38^{\circ} \mathrm{C}\left(100^{\circ} \mathrm{F}\right)$ during summer months. Published literature on GRCA hiking includes studies of social carrying capacity, ${ }^{11}$ heat illness, ${ }^{12-14}$ ranger acclimatization to heat, ${ }^{15}$ and hyponatremia $^{12,13,16,17}$; however, no studies were found on hiker demographics, behavior patterns, or physiologic changes in healthy individuals in desert environments, all of which may improve predictability of risk and help in development of targeted education by park rangers. 
A growing trend in GRCA wilderness travel is rim-torim (R2R) hiking or running, in which individuals attempt to hike or run from the North Rim of GRCA to the South Rim (or vice versa) in a single day. National Park Service (NPS) internal data and anecdotal reports from park staff have identified peak R2R hiking weekends of more than $1000 \mathrm{R} 2 \mathrm{R}$ hikers per weekend in the spring and fall. The highest traffic weekends surround the opening and closing of the North Rim in May and October, respectively. This journey covers 33.8 to $37.8 \mathrm{~km}$ ( 21.0 to $23.5 \mathrm{mi}$ ) depending on the chosen route, and visitors experience $1800 \mathrm{~m}(6000 \mathrm{ft})$ of elevation change as they descend into the canyon and ascend out the other side. Individuals hike the $22.9 \mathrm{~km}$ (14.2 mi) North Kaibab Trail on the north side of the canyon and choose between the $11.3 \mathrm{~km}$ (7.0 mi) South Kaibab Trail and the $15.3 \mathrm{~km}(9.5 \mathrm{mi})$ Bright Angel Trail on the south side of the canyon; the 3 trails intersect at Phantom Ranch, which sits next to the Colorado River at the canyon bottom at $756 \mathrm{~m}$ (2480 ft) in elevation. The North Kaibab Trailhead sits at $2512 \mathrm{~m}(8241 \mathrm{ft})$ in elevation, and the South Kaibab and Bright Angel Trailheads on the South Rim are 2213 m (7360 ft) and 2093 m (6860 $\mathrm{ft}$ ), respectively, meaning that northbound R2R participants ascend over $300 \mathrm{~m}$ more than southbound participants.

GRCA's emergency medical services (EMS) staff consists of paramedics, park medics, and EMT-Basics with additional wilderness medicine training. EMS providers respond to over 1100 EMS incidents and 300 search and rescue requests for assistance annually, with about 140 patients requiring helicopter evacuation. ${ }^{18} \mathrm{An}$ increase in the number of requests for emergency medical assistance for individuals attempting an R2R hike or run has placed substantial strain on rescue resources in GRCA. There are anecdotal reports of peak R2R weekends requiring every paramedic ranger in the park to respond to requests for assistance on the trails. There are also reported weekends in which solo rangers staffing backcountry ranger stations respond to requests for assistance throughout the day and evening and have limited rest, potentially increasing their risk of injury. The GRCA Preventive Search and Rescue team recently implemented additional staffing strategies with hopes of increasing hiker education and providing more rapid response to requests for assistance.

The purpose of this study was to characterize behavioral patterns of hikers and runners attempting to traverse the Grand Canyon from rim to rim in a single day to improve Preventive Search and Rescue rangers' ability to provide anticipatory guidance.

\section{Methods}

We conducted a prospective observational cohort study of visitors to the GRCA attempting an R2R crossing in a single day. Subjects were enrolled at 1 of the 3 main trailheads for this type of crossing: the North Kaibab trailhead on the north rim and either the Bright Angel Trailhead or South Kaibab trailhead on the south rim. Subjects at the trailhead were asked if they were planning an R2R crossing, and those self-identifying as attempting the crossing were then asked if they would like to participate in the study. Adults 18 y or over who assented to participation then provided verbal consent. Institutional review board approval was obtained from the University of New Mexico health sciences center human research protections office. An NPS research permit approved collection of data within NPS land, and office of management and budget approval was obtained for survey questions administered to NPS visitors.

There are 3 primary routes used to cross the Grand Canyon in a day. All 3 go through Phantom Ranch at the bottom of the canyon, and all 3 use the North Kaibab trail to connect the north rim to Phantom Ranch. This segment of the trail is the longest at about $22.9 \mathrm{~km}(14.2 \mathrm{mi})$. There are 2 main routes from Phantom Ranch to the South Rim: The South Kaibab trail is about $11.3 \mathrm{~km}(7.0 \mathrm{mi})$, and the Bright Angel Trail is about $15.3 \mathrm{~km}(9.5 \mathrm{mi})$.

Data were collected at the 3 trailheads over 2 weekends in 2015 from 0200 to 2200 on Saturday and Sunday of each study weekend. Participants were interviewed at the starting trailhead, canyon bottom, and exit trailhead. In addition to survey questions regarding nutrition, fitness, and hydration, simple biometric data were collected, including heart rate, pulse oximetry, and body weight. Fatigue was measured by self-report on a 10-point scale from none to worst possible. Other selfreported measures included perceived difficulty and preparedness, which were both measured on 5-point scales.

Data were collected on paper forms and included no identifiers. Data were later entered into a secure REDCap electronic capture system hosted at the University of New Mexico. ${ }^{19}$ This is in part supported through a Clinical Translational Science Center grant (DHHS/NIH/ NCRR \#8UL1TR000041).

Graphics were generated using Prism software version 6.07 (GraphPad, La Jolla, CA). Statistical analysis was performed using Stata version 13 (StataCorp 2013; College Station, TX). $P \leq 0.05$ determined significance. Categorical variables were tested for significance using a Fisher's exact test. Continuous variables were first analyzed for normality using the Shapiro-Wilk normality test. Normally distributed variables were analyzed using 
Table 1. Age and sex distribution of participants

\begin{tabular}{lcc}
\hline Age range (y) & Male & Female \\
\hline All & $65 \%$ & $35 \%$ \\
$18-30$ & $17 \%$ & $15 \%$ \\
$31-40$ & $21 \%$ & $24 \%$ \\
$41-50$ & $26 \%$ & $31 \%$ \\
$51-60$ & $25 \%$ & $22 \%$ \\
$61-75$ & $10 \%$ & $8 \%$ \\
\hline
\end{tabular}

the Student $t$ test or Pearson regression. Variables that did not meet normal distribution criteria were tested using a Mann-Whitney U test. Simple linear regression was used to evaluate the relationship between home elevation and $\mathrm{R} 2 \mathrm{R}$ completion times.

\section{Results}

A total of 617 participants enrolled in the study over 2 weekend days in May (325 participants) and 2 weekend days in October 2015 (292 participants). The median age of participants was $43 \mathrm{y}$ (interquartile range [IQR] $33-53$ years) (Table 1), and $65 \%$ of participants were male. The age distribution was similar between male and female participants (Figure 1). National Institutes of Health (NIH) body mass indices (BMI) for many participants, especially men, fell into the overweight categories (Table 2). Mean BMI was $25.3 \mathrm{~kg} \cdot \mathrm{m}^{-2}$ (IQR 23.6-27.7) for male participants and 22.8 (IQR 21.3-24.9) for female participants (Table 3 ).

More than one third of participants $(40 \%)$ had completed an R2R hike previously, with $33 \%$ of those participants having completed 5 or more R2R hikes (median 3, IQR 2-7). Forty-four participants (19\%) had completed 10 or more R2R hikes, 21 participants $(9 \%)$ had completed 20, and 1 had completed 46 (Table 4).

Start and finish times were used to determine how long individuals took to complete their hike and to evaluate ambient light exposure. The mean start time was 0530 (SD $1.3 \mathrm{~h}$ ); mean arrival time at Phantom Ranch at the bottom of the canyon was around 1030 $(\mathrm{SD} 2.2 \mathrm{~h})$; and mean finishing times were around 1730 (SD $2.0 \mathrm{~h}$ ) (Figure 2). The median canyon crossing time was $11.9 \mathrm{~h}$ (IQR 10.7-13.3) and did not differ by season (May vs October) (Figure 2). Uphill and downhill split times differed significantly between northbound and southbound hikers (Figure 2). Southbound hikers took approximately equal amounts of time to travel downhill and uphill (median $5.8 \mathrm{~h}$ downhill, $6.1 \mathrm{~h}$ uphill), whereas northbound hikers spent approximately one-third of their time traveling downhill $(4.3 \mathrm{~h})$ and two-thirds of their time traveling uphill $(7.6 \mathrm{~h})$. This is consistent with the South Rim to Phantom Ranch segment being shorter than the North Rim to Phantom Ranch segment.

Participants' self-reported hydration strategies are shown in Figure 3. Most participants reported hydrating with small sips of fluid throughout their hike and larger

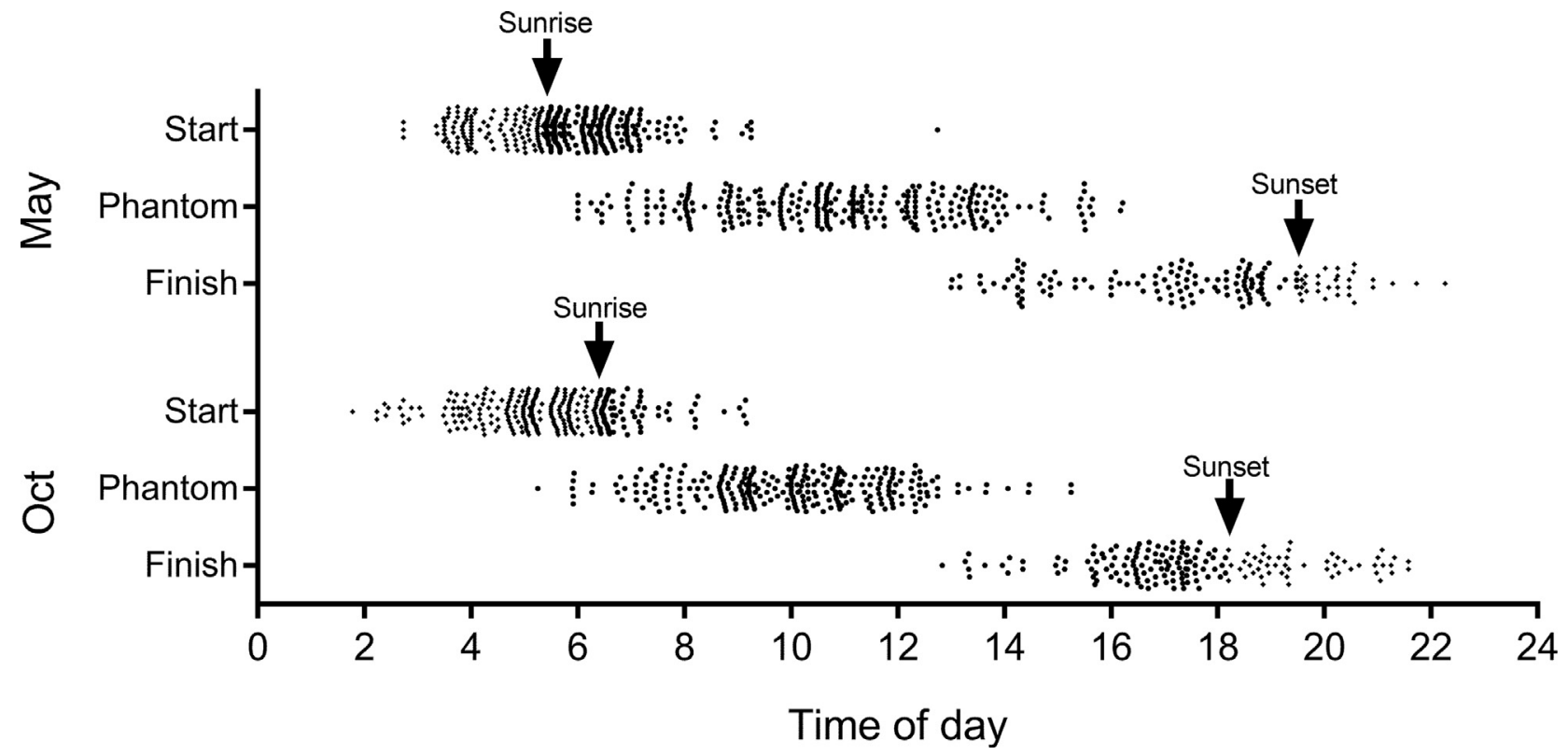

Figure 1. Time of day and sun exposure for participants. 
Table 2. Body mass index category

\begin{tabular}{lll}
\hline Category (BMI range) & Male $(\%)$ & Female $(\%)$ \\
\hline Underweight $(<18.5)$ & 0.3 & 5 \\
Normal $(18.5-24.9)$ & 45 & 71 \\
Overweight $(25-29.9)$ & 49 & 22 \\
Obese $(\geq 30)$ & 5 & 3 \\
\hline
\end{tabular}

BMI, body mass index.

amounts of fluid during meals. Nearly half of participants (48\%) used both water bottles and hydration bladder systems; participants who chose to use a single type of hydration system elected to use hydration bladders over water bottles ( $31 \%$ vs $20 \%$ ) (Figure 4). Overall, participants consumed a median of $3.3 \mathrm{~L}$ of fluid in total (IQR 1.0-5.1 L). Participants consumed approximately two-thirds of their fluid intake while traveling uphill (Figure 4).

Female participants consumed a median of $5.5 \mathrm{~mL} \cdot \mathrm{kg}^{-1}$ body weight per hour of hiking (IQR 4.1-7.2), and male participants consumed a median of $4.9 \mathrm{~mL} \cdot \mathrm{kg}^{-1}$ body weight per hour (IQR 3.7-7.0). Male and female participants did not differ in fluid consumption $(P=0.06)$. Female participants were consistent in the amount of fluid ingested over the time it took them to complete their hike $(P=0.30)$. The same was not true for men; the longer it took for male participants to finish their hike, the less fluid per kilogram body weight per hour they ingested $(P<0.0001)$ (Figure 5).

Self-reported fatigue was reported as a median of 7 (strong fatigue) with an IQR of 6 to 8 (somewhat strong fatigue to severe fatigue). Fatigue increased with crossing time $(P=0.04)$. (Figure 6). Participants who reported a more difficult hike also reported higher levels of fatigue at the end of their hike (Figure 6). Participants

Table 3. Age and weight characteristics

\begin{tabular}{llll}
\hline Characteristic & Median & IQR & $\mathrm{n}$ \\
\hline Age (all) & 43 & $33-53$ & 602 \\
Height $(\mathrm{m})$ & 1.75 & $1.68-1.83$ & 603 \\
$\quad$ Males & 1.80 & $1.75-1.83$ & 378 \\
Females & 1.65 & $1.63-1.70$ & 202 \\
Weight $(\mathrm{kg})$ & 77 & $66-86$ & 596 \\
$\quad$ Males & 82 & $75-89$ & 375 \\
$\quad$ Females & 63 & $58-71$ & 198 \\
Body mass index $\left(\mathrm{kg} \cdot \mathrm{m}^{2}\right)$ & 24.5 & $22.5-26.9$ & 592 \\
$\quad$ Male & 25.3 & $23.6-27.7$ & 374 \\
$\quad$ Female & 63 & $58-71$ & 198 \\
\hline
\end{tabular}

IQR, interquartile range.
Table 4. Participant's previous crossing experience

\begin{tabular}{ll}
\hline Number of previous R2R crossings & Percentage \\
\hline None & 61 \\
$1-2$ & 19 \\
$3-4$ & 7 \\
$5-10$ & 7 \\
$>10$ & 6 \\
\hline
\end{tabular}

$\mathrm{R} 2 \mathrm{R}$, rim to rim.

who self-reported feeling underprepared or somewhat underprepared were more likely to report stronger fatigue than those who felt they were somewhat over or overprepared (Figure 6). Additionally, participants with previous R2R experience reported lower fatigue at the end of their hike $(P<0.01)$ (Figure 6$)$. We evaluated a hypothesized relationship of home elevation vs finishing time using simple linear regression. We showed a modest negative correlation with increasing home altitude $(P=0.021)$ with an equation of $\mathrm{Y}=-126.5 * \mathrm{X}+3431$. This indicates that a higher home elevation is associated with faster travel times.

\section{Discussion}

R2R hiking mirrors the challenges of a trail marathon or ultramarathon. The age of $\mathrm{R} 2 \mathrm{R}$ hikers was similar to that of ultramarathoners, but BMI was higher in the R2R group. ${ }^{20} \mathrm{We}$ recognize that NIH BMI categories are somewhat controversial because they do not adequately account for body composition. They are reported here for comparison to other studies and not to comment on
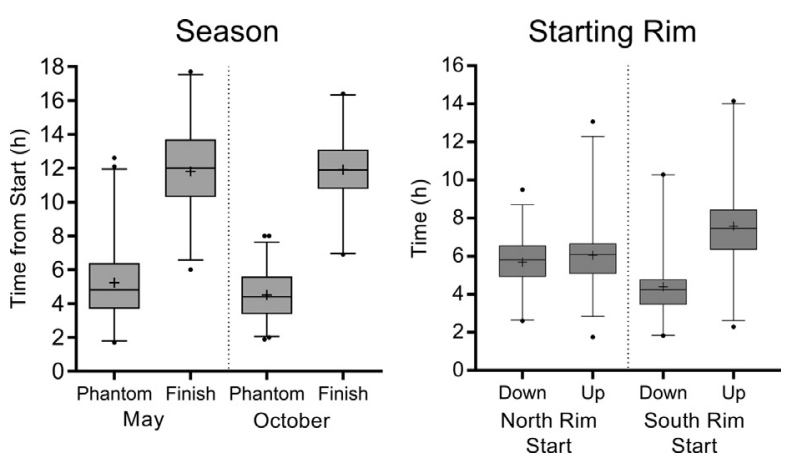

Figure 2. Travel times by season or starting rim (whiskers represent the first to 99th percentiles). Median travel times to Phantom Ranch from the rim were slightly shorter in October, by $24 \min (P<0.01$, Mann-Whitney $U$ test), but total time to finish was not different between October and May. Travel times from the rim to the bottom and from the bottom to the rim were significantly different based on starting $\operatorname{rim}(P<0.0001$, Mann-Whitney $\mathrm{U})$. 


\section{Reported Agreement Hydration Strategy}

I think I drank too much fluids during my hike
I only consumed fluids with a meal or a snack
I only drank fluids whenever I was thirsty and only amounts in order to quench my thirst

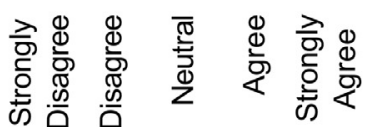

Figure 3. Self-reported hydration strategies.

hiker fitness. For emergency personnel, this has important implications for emergency preparedness in the canyon.

Experienced hikers who have completed an R2R before may have greater perspective on the challenges of the hike and are understandably more prepared. It can be hypothesized that these participants may have trained more, or more effectively, than first-time participants, leading to their lower reported fatigue and hike difficulty. Inexperienced hikers would benefit from traveling with hikers who have completed a prior R2R.

With hikers starting in the early morning hours, slower hikers effectively place themselves in the hottest part of the canyon in the hottest part of the day. These slower

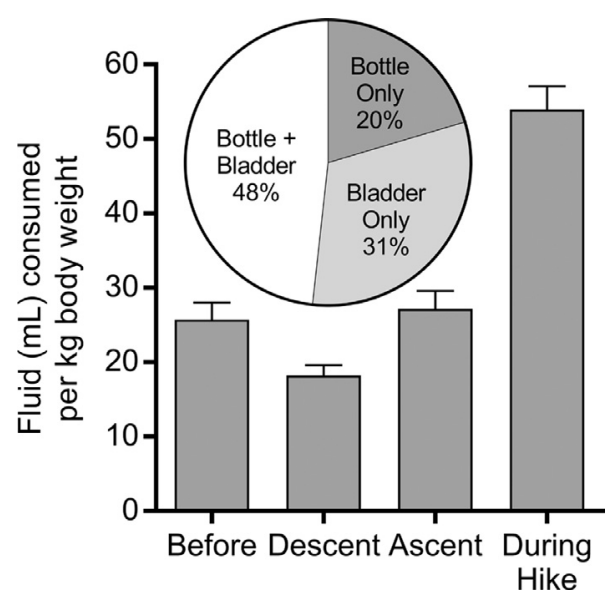

Figure 4. Fluid consumption strategies. hikers may choose to do their hike in the fall, with shorter daylight hours, to minimize sun exposure. Additionally, hikers may elect to start their hike in the evening, crossing the canyon at night rather than during the day. This strategy may be safer from a heat-illness standpoint, but for individuals inexperienced in traveling by headlamp, it may pose greater risks for traumatic injuries from falls. Information gained in this study concerning the distribution of hikers by time of day will allow park rangers to more effectively staff resources on the trails; it may be prudent to place a ranger on the trail in the earlier morning hours to educate inexperienced hikers before they are too far into their hike.

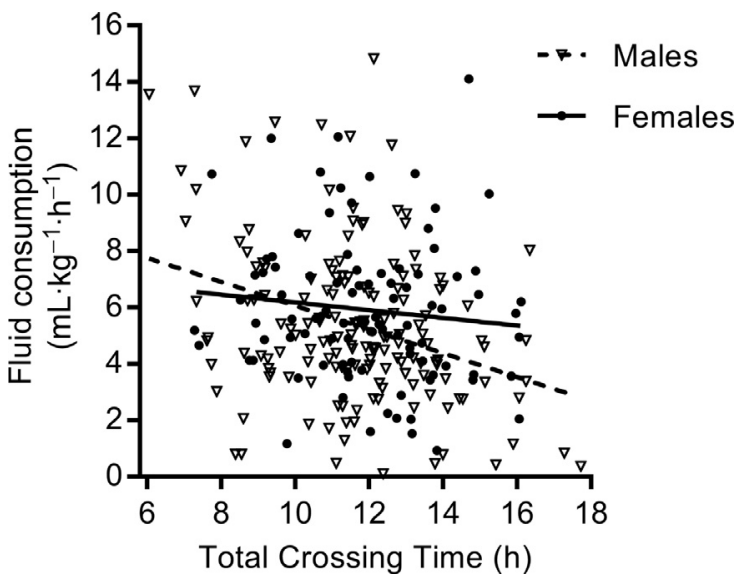

Figure 5. Fluid intake $(\mathrm{mL})$ of participants per $\mathrm{kg}$ of body weight per hour of hiking, by sex. 


\section{Overall Distribution of Finish Fatigue (from none to worst possible)

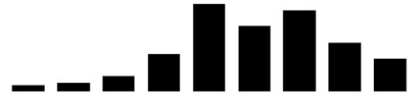

\section{Have you previously hiked a R2R?}

$p<0.01$ Spearman $r(95 \% \mathrm{Cl})-0.12(-0.22-0.03)$

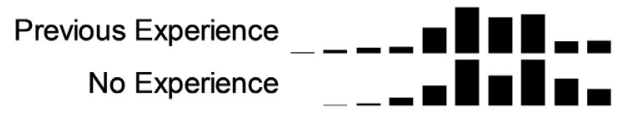

Answer anchors

Fatigue Distribution

How prepared were you?

$p<0.01$ Spearman r $(95 \% \mathrm{Cl})-0.27(-0.36--0.18)$

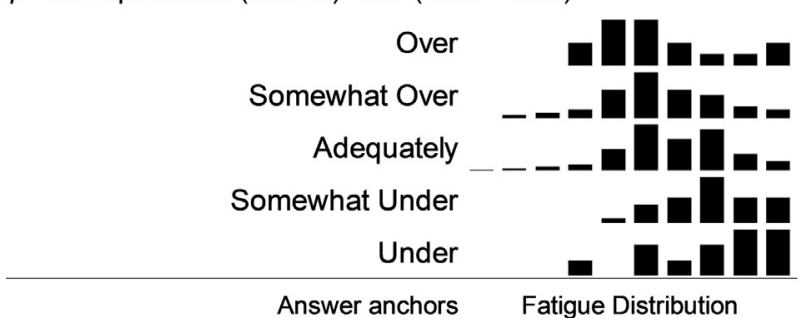

\section{Time to finish}

$p<0.01$ Spearman $r(95 \% \mathrm{CI}) 0.17(0.05-0.28)$

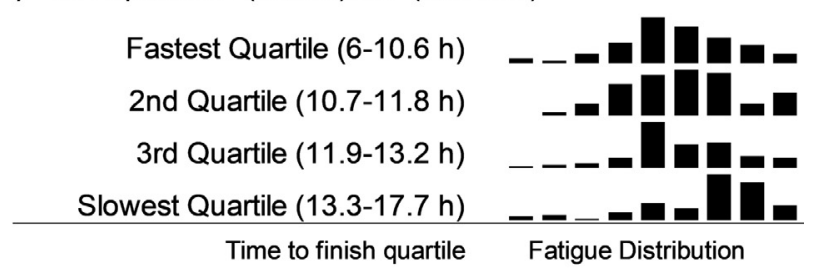

How difficult was the hike?

$p<0.01$ Spearman r $(95 \% \mathrm{Cl}) 0.38(0.29-0.46)$

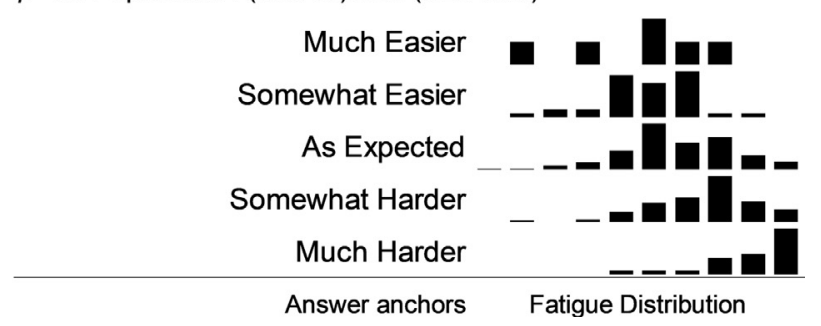

Figure 6. Correlates of finish fatigue.

We were surprised to find no significant difference in finish times between northbound and southbound hikers considering the marked differences between the elevations of the North Rim and South Rim. This should mean that northbound hikers have an additional 20 to $30 \%$ greater ascension, which we initially suspected would lead to slower northbound times compared with southbound times. Although the total finish time had no significant difference, it is interesting to compare the differences in uphill and downhill splits between northbound and southbound hikers. Southbound hikers travel $22.9 \mathrm{~km}(14.2 \mathrm{mi})$ downhill and $11.3 \mathrm{~km}(7.0 \mathrm{mi})$ or $15.3 \mathrm{~km}(9.5 \mathrm{mi})$ uphill, depending on route choice; with faster downhill paces, they split their time relatively evenly between uphill and downhill travel. Northbound hikers, however, travel $11.3 \mathrm{~km}(7.0 \mathrm{mi})$ or $15.3 \mathrm{~km}$ (9.5 mi) downhill and then $22.9 \mathrm{~km}$ (14.2 mi) uphill and, as a result, spend two-thirds of their time hiking uphill. This route may be more advisable for hikers with orthopedic concerns who prefer to minimize the time spent traveling downhill and thus reduce mechanical stress on their joints.

Interestingly, a large percentage of hikers chose to solely use a hydration bladder (32\%). Hydration bladders, compared with water bottles, make it easier for hikers to sip frequently while walking, which may explain their popularity. We consider the singular use of hydration bladders in the desert to be high risk because the tough and spiny desert environment has ample opportunity to pierce the sides of a hydration bladder, leaving the hiker with no reserve water supply. Furthermore, it is not unheard of for plastic water bottles to crack as well; thus, we would recommend that all hikers carry at least 2 fluid reservoirs, either as bottles or a combination of bottles and a hydration bladder.

Because hikers consume most their fluid intake during uphill energy expenditure, it is prudent for hikers to be more conscientious about carrying adequate water or locating sources of water on long, uphill sections of hikes. Quantifying an appropriate amount of fluid intake is a question that requires more research because necessary fluid intake appears to differ greatly from person to person. This study contributes by showing variations in fluid intake by sex and time spent hiking. Interestingly, time spent hiking was negatively associated with hydration volume per hour among male hikers but not among female hikers. This implies that male participants who are slower, and thus perhaps less fit, are also less adept at 
maintaining consistent hydration strategies. Overall, however, the hydration strategies of hikers require further investigation.

Hikers who had completed a previous R2R hike reported lower levels of fatigue at the finish than hikers who had no previous experience. This implies that hikers with experience may have trained more; additionally, there was likely less psychological stress of traveling in an unfamiliar backcountry environment.

A correlation between lower home elevations and slower hiking times suggests that hikers from lower elevations may benefit from a period of acclimatization before beginning their hike. Furthermore, the effects of travel, which may include jet lag, limited sleep or rest, and different environmental conditions than home acclimatization, may also contribute to hiking success and fatigue.

\section{LIMITATIONS}

The study was performed during 2 of the busiest weekends for single-day transcanyon travel. These weekends were chosen for that reason, but this limits the generalizability of our findings to early and late season travel. Further studies evaluating the effect of a broader range of environmental conditions are warranted to increase the generalizability of the findings. Another limitation is the possible selection bias of participants willing to enroll in the study. Subjects who were significantly underprepared may not have wanted to participate for fear of being stopped from crossing. If this were the case, we would expect that our sample would differ significantly from the characteristics of those requiring rescue. This comparison is a valuable future direction for this work. Our sample was large, and the number of first-time crossers suggests we had adequate penetration of the population. The biggest limitation is that this study was primarily survey based. Future studies should include additional objective measures such as blood chemistries to better understand the physiologic effect on R2R crossers.

\section{Conclusion}

Visitors to the GRCA attempting to traverse the canyon from rim to rim in a single day start early in the morning and are exposed to the highest temperatures during the most difficult part of the hike. Visitors would benefit from beginning their hike early, traveling with experienced hikers, acclimating to elevation, and hydrating appropriately. Preventive search and rescue educational strategies may be improved through more accurate visitor education about the time required to complete an R2R hike and the difficulty of the hike. Further analysis of nutritional and hydration data may lead to more defined recommendations for hydration in a southwest desert environment.

Acknowledgments: This work could not have been accomplished without the dedicated volunteerism of members of the Grand Canyon Association, Grand Canyon's Preventive Search and Rescue volunteers, University of New Mexico students, and community members. This work is dedicated to the hardworking park rangers of Grand Canyon National Park, who demonstrate a passion for conservation and a continuous dedication to resource protection and public safety.

Author Contributions: Conception and design (EAP, CJM, HLH, EJL, AP, MH, CSB, AJH, JKF); acquisition of data (EAP, CJM, HLH, EJN, AP, MH, CSB, ES, AJH, JKF, LJ); data analysis and interpretation (EAP, JKF, CSB, AJH, JKF); article drafting, review, and approval (EAP, LJ, LF, CJM, HLH, EJN, AP, MH, CSB, ES, AJH, JKF).

Financial/Material Support: This material was funded through Dr. Jon Femling's discretionary research funds from the University of New Mexico. This material is the result of work supported with resources and the use of facilities of the University of New Mexico School of Medicine and the Grand Canyon National Park Preventive Search and Rescue Team. The contents reported here do not represent the views of Grand Canyon National Park, the National Park Service, or the United States Government.

Disclosure: We disclose Dr Harrell and Ms Pearce's relationship with Grand Canyon National Park Branch of Emergency Services as members of their EMS medical direction group.

\section{References}

1. Gardner TB, Hill DR. Illness and injury among long-distance hikers on the Long Trail, Vermont. Wilderness Environ Med. 2002;13(2):131-4.

2. Legg SJ, Ramsey T, Knowles DJ. The metabolic cost of backpack and shoulder load carriage. Ergonomics. 1992;35 (9):1063-8.

3. Vacheron JJ, Poumarat G, Chandezon R, Vanneuville G. The effect of loads carried on the shoulders. Mil Med. 1999;164(8):597-9.

4. Hackett PH, Roach RC. High-altitude illness. N Engl J Med. 2001;345(2):107-14.

5. Hargarten S. Injury control research and wilderness medicine: a babe dangling in the woods. Wilderness Environ Med. 1999;10(1):2.

6. Mason RC, Suner S, Williams KA. An analysis of hiker preparedness: a survey of hiker habits in New Hampshire. Wilderness Environ Med. 2013;24(3):221-7.

7. Malcolm CJ, Heinrich H, Pearce EA. Effectiveness of preventive search and rescue: illness and injury prevention and fiscal impact. Wilderness and Environ Med. 2014;25 (3):356

8. Malcolm CJ, Heinrich H, Pearce EA. Physiological temperature thresholds and heat-related hiker assists-preventive search and rescue in Grand Canyon National Park. Wilderness and Environ Med. 2014;25(3):356.

9. Twombly SE, Schussman LC. Gender differences in injury and illness rates on wilderness backpacking trips. Wilderness Environ Med. 1995;6(4):363-76.

10. Crouse BJ, Josephs D. Health care needs of Appalachian trail hikers. J Fam Pract. 1993;36(5):521-5. 
11. Towler WL. Hiker perception of wilderness: A study of the social carrying capacity of Grand Canyon. Arizona Review. 1977;26(8-9):1-10.

12. Backer HD, Shopes E, Collins SL. Hyponatremia in recreational hikers in Grand Canyon National Park. Wilderness Environ Med. 1993;4(4):391-406.

13. Backer HD, Shopes E, Collins SL, Barkan H. Exertional heat illness and hyponatremia in hikers. Am J Emerg Med. 1999;17(6):532-9.

14. Noe RS, Choudhary E, Cheng-Dobson J, Wolkin A, Newman S. Exertional heat-related illnesses at the Grand Canyon National Park, 2004-2009. Wilderness Environ Med. 2013;24(4):422-8.

15. Krake AM, McCollough JE, King BS. Health hazards to park rangers from excessive heat at Grand Canyon National Park. Appl Occup Environ Hyg. 2003;18(5): 295-317.
16. Shopes EM. Drowning in the desert: exercise-induced hyponatremia at the Grand Canyon. J Emerg Nurs. 1997;23(6):586-90.

17. Pearce EA, Myers TM, Hoffman MD. Three cases of severe hyponatremia during a river run in Grand Canyon National Park. Wilderness Environ Med. 2015;26(2):189-95.

18. National Park Service. 2015 Annual Report: Grand Canyon National Park Branch of Emergency Services. Grand Canyon National Park Arizona: Grand Canyon, AZ; 2015.

19. Harris PA, Taylor R, Thielke R, Payne J, Gonzalez N, Conde JG. Research electronic data capture (REDCap)-a metadata-driven methodology and workflow process for providing translational research informatics support. J Biomed Inform. 2009;42(2):377-81.

20. Hoffman MD, Fogard K. Demographic characteristics of 161-km ultramarathon runners. Res Sports Med. 2012;20 (1):59-69. 